\title{
Consumption of melatonin supplement improves cardiovascular disease risk factors and anthropometric indices in type 2 diabetes mellitus patients: A double- blind, randomized, placebo-controlled trial
}

Hadi Bazyar

Ahvaz Jundishapour University of Medical Sciences

Ahmad Zare Javid

Ahvaz Jundishapour University of Medical Sciences

Hossein Bavi Behbahani

Ahvaz Jondishapour University of Medical Sciences

\section{Fardin Moradi}

Ahvaz Jondishapour University of Medical Sciences

\section{Bahman Moradi Poode}

Tabriz University of Medical Sciences

parichehr amiri ( $\square$ amiriparichehr70@gmail.com )

Ahvaz Jundishapour University of Medical Sciences https://orcid.org/0000-0003-4230-9383

\section{Research}

Keywords: Type 2 diabetes mellitus, Melatonin, Blood pressure, New anthropometric indices

Posted Date: November 11th, 2020

DOI: https://doi.org/10.21203/rs.3.rs-18733/v2

License: (c) (i) This work is licensed under a Creative Commons Attribution 4.0 International License. Read Full License

Version of Record: A version of this preprint was published on March 25th, 2021. See the published version at https://doi.org/10.1186/s13063-021-05174-z. 


\section{Abstract}

Background: Diabetes mellitus is a common chronic disease. Dyslipidemia and hypertension are two complications that may develop in diabetic patients if hyperglycemia, insulin resistance, and weight gain are not controlled. This study investigated the effects of melatonin supplementation on some cardiovascular disease risk factors and anthropometric indices in patients with type 2 diabetes mellitus (T2DM).

Materials and Methods: In this double-blind, randomized, placebo-controlled trial, 50 T2DM patients were randomly allocated to intervention and control groups which received two tablets of either melatonin or placebo (250 mg) once a day for eight weeks. Mean arterial pressure (MAP), pulse pressure (PP), the atherogenic index of plasma (AIP), weight, body mass index (BMI), waist and hip circumference (WC, HC), body shape index (ABSI), abdominal volume index (AVI), body adiposity index (BAI), lipid accumulation product (LAP), conicity index, and waist-to-height ratio (WHR) were evaluated in all the patients pre- and post-intervention.

Results: Melatonin supplementation for eight weeks significantly decreased the mean levels of MAP, PP, weight, BMI, WC, HC, BAI, AVI, conicity index, and WHR post-intervention ( $p<0.05)$. Also, the median changes of MAP, PP, weight, $\mathrm{BMI}, \mathrm{WC}, \mathrm{HC} B A \mathrm{BV}, \mathrm{VI}$, and conicity index were significantly lower in the intervention group compared with the control group ( $p<0.05)$. A significant increase $(p<0.001)$ was observed in the mean levels of $A B S I$ in the intervention group. The median changes of ABSI were significantly greater in the intervention group compared with the control group $(p<0.001)$.

Conclusions: Consumption of melatonin supplement may be effective in controlling arterial pressure and anthropometric indices (as predictors of obesity) in T2DM patients.

Trial registration: This trial was registered in the Iranian Registry of Clinical Trials website at 2019/5/17. (IRCT20190303042905N1).

\section{Background}

There are clusters of metabolic abnormalities in type 2 diabetes mellitus (T2DM), including hyperglycemia, insulin resistance, and inflammation, which increase the risk of cardiovascular disease (CVD) [1]. CVD is one of the most important causes of mortality and morbidity among diabetic patients [2]. The prevalence rate of CVD in adults with diabetes is more than in adults without diabetes, and there is a strong association between increased fasting plasma glucose with a heightened risk of CVD [3]. On the other hand, T2DM patients are at a higher risk of developing dyslipidemia which is an important risk factor for coronary artery disease (CAD) [4]. Abnormal levels of serum lipids and lipoproteins may accelerate the progression of atherosclerosis in T2DM [3]. The atherogenic index of plasma (AIP) has recently been used as a better predictor of plasma atherogenicity [5]. AIP is defined as the logarithm [log] of the ratio of triglyceride (TG) levels to high-density lipoprotein (HDL) cholesterol. Studies indicate that there is a positive correlation between AIP and the risk of CVD [6].

Moreover, it was reported that T2DM and hypertension (HTN) may co-exist in some patients. The prevalence of HTN is approximately $30 \%$ in patients with T2DM [7]. The mean arterial pressure (MAP) reflects both peripheral resistance and cardiac output [8]. According to the "ADVANCE trial" [9], MAP was correlated with major CVD events, such that a $13 \%$ increase in risk was observed with a $13 \mathrm{mmHg}$ increase in MAP. Pulse pressure (PP), the other indicator of CVD risk, is considered as a manifestation of arterial stiffness. Overall, in T2DM, dyslipidemia and HTN are considered as both quantitative and qualitative abnormalities including abnormal plasma levels of lipid profile 
and changes in the composition of lipoproteins [10], change that may lead to endothelial dysfunction and atherosclerosis $[7,11]$.

Melatonin is a neurohormone mostly secreted by the pineal gland and also locally by many other tissues during night [12]. In addition to the regulation of circadian rhythms, melatonin has other regulatory roles in inflammation, immune system, and oxidative stress [13-16]. Mukherjee et al. proposed that melatonin can provide cardioprotection at low pharmacological doses [17]. The ability of melatonin to improve cardiovascular function and its hypotensive effect because of its direct antioxidant and receptor-dependent actions suggest that melatonin may have some beneficial effects on controlling diabetic vascular complications $[18,19]$. Moreover, animal studies pointed out that melatonin may reduce body weight and fat mass, regulate energy expenditure, glucose/lipid metabolism, and insulin secretion; therefore, it may play an effective role in weight management [20-22].

Obesity can be defined by different anthropometric measurements and indices. Recently, there has been growing speculation over which indices in obesity can calculate the CVD risk better [23]. Evidence from statistical analysis indicates that in order to detect CVD risk factors in populations, the measurements of centralized obesity (such as waist circumference (WC), waist-to-hip ratio (WHR), or waist-to-height ratio (WHtR)) are preferred to body mass index (BMI) [23-27]. Furthermore, many new anthropometric indices such as body shape index (ABSI), abdominal volume index (AVI), body adiposity index (BAI), lipid accumulation product (LAP) have been developed recently. These measures have been proven to be complementary indices to BMI and other known risk factors $[28,29]$. In this study, we investigated the effects of melatonin supplementation on some CVD predictors such as MAP, PP, AIP, and anthropometric indices in T2DM patients.

\section{Material And Method}

\section{Participants}

In this double-blinded, placebo-controlled trial, 96 T2DM patients were recruited from the endocrinology and metabolism clinics of Golestan Hospital of Ahvaz Jundishapur University of Medical Science, Iran. Fifty participants were selected based on the inclusion criteria (Fig. 1).

The FBS $\geq 126 \mathrm{mg} / \mathrm{dl}$ and HbA1c $\geq 6.5 \%$ or 2-hglucose $(2 \mathrm{hpp}) \geq 200 \mathrm{mg} / \mathrm{dl}$ were used as the criteria to define diabetes mellitus (DM) [30]. The inclusion criteria were: male or female, age of 30-60 years old, BMI 18.5-30 kg/m², and having DM (for more than five years since the diagnosis). The exclusion criteria were having kidney and thyroid diseases, traveling for more than two weeks, pregnancy and lactation, smoking, having consumed alcohol over the past year, using medications such as immunosuppressive agents, insulin, anti-inflammatory drugs, and dietary supplements, and remarkable changes in using medications and treatment of diabetes or considerable changes in diet over the past six months. The compliance of the participants was assessed by counting the remaining tablets. Participants who consumed $<90 \%$ of the prescribed tablets were excluded.

The participants were allocated to intervention $(n=25)$ or placebo $(n=25)$ groups by a random block design. Accordingly, all the participants were assigned to six groups with four blocks in two steps plus two separate subjects using two codes of $A$ and $B$ according to the block design ( $A A B B, B B A A, A B A B, B A B A, A B B A, B A B A$ ). Randomization was performed by an independent third person in the health-care system who was not informed of the study. The researchers and patients were not informed of the allocation of participants to the groups (doubleblinded). The participants in the intervention and control groups received $250 \mathrm{mg}$ of either melatonin supplement (containing sodium starch glycolate, magnesium stearate, and $3 \mathrm{mg}$ of net melatonin; purchased from the National 
Vitamin Company, Nature Made, USA) or placebo tablets (containing a few drops of peppermint oil, manufactured in the Faculty of Pharmacy, Ahvaz Jundishapur University of Medical Sciences, Iran). The melatonin and placebo tablets were prescribed for eight weeks as two tablets once a day one hour before bedtime. In terms of size, color, taste, and shape, the placebo and melatonin tablets were matched. The participants were asked to report any probable side effects of supplementation throughout the study. Patients were advised to follow any prescribed treatment and diabetic diet, and not to change their usual physical activity and diet pattern during the study.

\section{Blood pressure (BP), mean arterial pressure (MAP), and pulse pressure (PP)}

BP was recorded in a relaxed sitting position on the left arm after at least a 5 min rest using a mercury sphygmomanometer. The measurement was repeated twice, and the mean of the two measurements was considered as the BP. MAP and PP were calculated according to the following equations [8, 9]:

$\mathrm{MAP}(\mathrm{mmHg})=[\mathrm{SBP}+(2 \times \mathrm{DBP})] / 3$

$\mathrm{PP}(\mathrm{mmHg})=\mathrm{SBP}(\mathrm{mmHg})-\mathrm{DBP}(\mathrm{mmHg})$

\section{Traditional and new anthropometric indices and nutritional assessment}

All anthropometric measurements were performed by a trained nutritionist. Traditional anthropometric indices included height, weight, BMI, WC, and HC. Height (without shoes in a standard situation with a precision of $0.1 \mathrm{~cm}$ ) and weight (by Seca scales, with light clothes, and a precision of $0.1 \mathrm{~kg}$ ) were measured. BMI was calculated as weight $(\mathrm{Kg}) /$ height $\left(\mathrm{m}^{2}\right)$. WC as the smallest horizontal girth between the costal and iliac crests was measured using a non-stretchable measuring tape at minimal respiration. Hip circumference, as the greatest circumference at the level of greater trochanters (the widest portion of the hip) on both sides, was also measured.

All calculations for new anthropometric indices (ABSI, AVI, BAl, conicity, LAP, and WHR) were performed according to the following equations [31]:

$$
\begin{aligned}
& \text { A body shape index }(\mathrm{ABSI})=\frac{\text { wc }}{\mathrm{BMI}^{2 / 3} \times \text { height }^{1 / 2}} \\
& \text { Abdominal volume index }(\mathrm{AVI})=\left[2\left(\mathrm{WC}^{2}\right)+0.7(\text { waist } / \mathrm{hip})^{2}\right] / 1000 \\
& \text { Body adiposity index }(\mathrm{BAI})=\frac{\text { hip }}{\text { height }^{1.5}}-18 \\
& \text { Conicity }=\frac{\mathrm{WC}(\mathrm{m})}{0.109 \sqrt{\frac{\text { weight }(\mathrm{kg})}{\text { height }(\mathrm{m})}}}
\end{aligned}
$$

lipid accumulation product $(\mathrm{LAP})$ for men $=[\mathrm{WC}(\mathrm{cm})-65] \times[$ Triglyceride $(\mathrm{mM})]$

LAP for women $=[\mathrm{WC}(\mathrm{cm})-58] \times[$ Triglyceride $(\mathrm{mM})]$

Waist-to-height ratio (WHR): WC (cm) / height (cm)

A 3-day 24-h dietary recall was also obtained for dietary assessment at the beginning and end of the study. The Nutritionist IV software (Axxya Systems, Stafford, Texas, USA), modified for Iranian foods, was used for dietary data analysis.

\section{Atherogenic index of plasma (AIP(}


AIP was obtained by dividing the logarithmically transformed ratio of triglycerides (TGs) / high-density lipoprotein cholesterol

$(\mathrm{HDL}-\mathrm{C})\left(\mathrm{AIP}=\log \frac{\mathrm{TG}}{\mathrm{HDL}}[5]\right.$.

All the measurements and calculations were repeated after the intervention at the end of the study.

\section{Blood sampling and biochemical measurements}

Blood samples of $2 \mathrm{cc}$ were collected from all the participants after fasting overnight for at least 12 hours, and were centrifuged at $3000 \mathrm{rpm}$ for $5 \mathrm{~min}$. The lipid profile parameters were immediately measured using Pars Azmoon kits (Pars Azmoon, Tehran, Iran). The serum concentrations of TG and HDL-C were determined through an enzymatic procedure using glycerol phosphate oxidase and phosphotungstic acid, respectively.

\section{Statistical analysis}

Statistical analyses were performed using SPSS software version 19.0 for Windows (PASW Statistics; SPSS Inc., Chicago, IL, USA). Analyses were conducted via an intention-to-treat (ITT) approach. The Kolmogorov-Smirnov test was used to check the normality of the data. An independent sample t-test and a paired sample t-test were also performed to compare the normal variables between and within groups, respectively, at baseline and after intervention. Post-intervention, the analysis of covariance (ANCOVA) was done to compare the results between the two groups after adjustment for confounding factors. We used two models, a crude model (without adjust) and with adjustment with age, sex, job, education, energy, physical activity, drugs, and disease duration (Model 1). A chisquare test was also used to compare the categorical variables. Data are expressed as mean \pm standard deviation (SD) for normal distributions and median (Q1-Q3) for abnormal distributions. A Mann-Whitney U test was performed to compare changes between the two groups after the intervention. P-values $<0.05$ were deemed significant.

Based on Ramezanpour et al.'s study [32], with 5\% a (confidence interval of 95\%) and 80\% power of study, and considering SBP as the primary outcome, according to this formula:

$$
n=\frac{\left(z_{1}-\frac{\alpha}{2}+z_{1}-\beta\right)^{2}\left(\delta_{1}{ }^{2}+\delta_{2}{ }^{2}\right)}{\left(\mu_{1}-\mu_{2}\right)^{2}}
$$

the sample size was estimated to be 21 participants for each group; however, considering a $20 \%$ withdrawing rate, we selected 25 participants in each group.

\section{Results}

Out of the 50 patients included in the study, six patients were excluded (three patients discontinued intervention, and three patients did not use the supplement or placebo). However, in the end, the final analysis was performed with the same 50 patients using the ITT method. The percentage of female participants was about $68.18 \%$ in the two groups $(p=0.51)$. The mean age of the participants was matched between the two groups ( $51.45 \mathrm{vs.} 53.71 \mathrm{y})$. There were no significant differences in terms of age and anthropometric indices between control and intervention groups at the baseline (Table 1). Also, dietary parameters including total energy, total fat, protein, and carbohydrate intakes did not differ between the two groups at the baseline (Table 2). 


\section{The effects of melatonin on mean arterial pressure (MAP), pulse pressure (PP), atherogenic index of plasma (AIP)}

Melatonin supplementation significantly decreased the mean levels of MAP (84.80 \pm 8.33 vs $90.66 \pm 9.90$, respectively; $p=0.003)$ and PP $(50.00 \pm 11.54$ and $44.40 \pm 11.21$, respectively; $p=0.02)$. The mean of MAP was significantly lower in the intervention group compared with the control group post-intervention (84.80 \pm 8.33 vs $91.33 \pm 8.81$, respectively; $p=0.01)$. Also, this result remained significant after the adjustment of confounding factors $(p=0.009)$. The median (Q1-Q3) changes of MAP $(-3.33(-10.00,0.00)$ vs $0.00(-3.33,3.33)$, respectively; $\mathrm{P}=$ $0.005)$ was significantly lower in intervention group in compare with control group.The mean of PP was not significantly different in the intervention group compared with the control group post-intervention $(p>0.05)$. But the median (Q1-Q3) changes of PP $(0.00(-10.00,0.00)$ vs $0.00(-10.00,10.00)$, respectively; $p=0.03)$ was significantly lower in intervention group in compare with control group. No significant differences were observed in AIP within and between both groups $(p \geq 0.05)$. (Table3).

\section{The effects of melatonin on anthropometric indices}

Weight (70.28 \pm 7.57 vs $73.88 \pm 8.85$ respectively; $p=0.001)$, $\mathrm{BMI}(26.11 \pm 2.39$ vs $27.38 \pm 2.16$ respectively; $p=$ $0.002)$, WC (99.48 \pm 9.54 vs $101.60 \pm 10.07$ respectively; $p=0.01), \mathrm{HC}(103.04 \pm 9.32$ vs $106.76 \pm 10.04$ respectively; $p=0.001)$, BAI (19.96 \pm 3.85 vs $20.84 \pm 4.10$ respectively; $p=0.01), \operatorname{AVI}(19.96 \pm 3.85$ vs $20.84 \pm 4.10$, respectively; $p$ $=0.01)$, Conicity $(1.39 \pm 0.08$ vs $1.42 \pm 0.08$, respectively; $p=0.001)$ and WHR $(0.60 \pm 0.05$ vs $0.60 \pm 0.05$, respectively; $p=0.02$ ) were significantly decreased post intervention.

The mean of BMI was significantly lower in the intervention group compared with the control group postintervention $(26.11 \pm 2.39$ vs $27.47 \pm 2.03$ respectively $p=0.03)$. Also, this result remained significant after the adjustment of confounding factors $(p=0.04)$.

The median (Q1-Q3) changes of weight $(-3.00(-6.50,-1.50)$ vs $-1.00(-1.00,1.00)$, respectively; $p<0.001), \mathrm{BMI}(-1.17$ $(-2.40,-0.51)$ vs $-0.30(-0.39,0.42)$, respectively; $p<0.001)$, WC $(-1.00(-3.00,0.00)$ vs $0.00(-1.00,1.00)$, respectively; $p$ $=0.003), \mathrm{HC}(-2.00(-5.00,-1.00)$ vs $0.00(-1.00,1.00)$, respectively; $p<0.001), \operatorname{AVI}(-0.45(-1.10,0.00)$ vs $0.00(-0.42$, $0.40)$, respectively; $p=0.004)$, BAI $(-3.38(-5.36,-0.92)$ vs $-1.04(-3.33,0.45)$, respectively; $p=0.04)$, Conicity $(-0.01$ $(-0.04,0.00)$ vs $0.00(-0.01,0.01)$, respectively; $p=0.003)$ and WHR $(-0.006(-0.018,0.000)$ vs $0.00(-0.006,0.006)$, respectively; $p=0.01$ ) were significantly lower in the intervention group in compare with the control group (Table3).

A significant increase was observed in the mean levels of ABSI in the intervention group $(0.04 \pm 0.004$ and $0.037 \pm$ 0.005 , respectively; $p<0.001)$. The median (Q1-Q3) changes of ABSI was significantly greater in the intervention group compared with the control group $(0.002(0.001,0.005)$ vs $0.000(-0.001,0.001)$, respectively; $p<0.001)$ (Table3).

\section{Discussion}

This study was the first to investigate the effects of melatonin supplementation on predictors of CVDs in T2DM patients. In this study, AIP did not change. Although melatonin increased the HDL levels, the changes in AIP were not significant. There is evidence on the effect of melatonin on lipid profile and metabolism; however, such data are mainly reported from animal studies [33-35], and the results are controversial in humans [36-39]. Consistent with our study, Tamura et al. reported positive results regarding HDL post-consumption of $1 \mathrm{mg}$ of melatonin; still, no improvement was observed in terms of total cholesterol and TG levels in pre- and post-menopausal women [38]. Also, Garfinkel et al. [37] reported no changes in TG levels in type 2 diabetic patients after receiving 2 mg of 
melatonin supplement. In another study, Rezvanfar et al. reported that HDL level was increased in response to melatonin, while no changes were observed in the other lipid profile parameters [39].

The results of this study showed that melatonin supplementation for eight weeks significantly decreased MAP and PP. In Możdżan et al.'s study conducted on diabetic patients with HTN, the hypotensive effect of melatonin on MAP was reported to be significant at two dosages of 3 and $5 \mathrm{mg}[40]$.

Previous studies proposed that melatonin can regulate BP through multiple mechanisms. First, melatonin can directly act as a free radical scavenger and provide appropriate concentrations of nitrogen oxide (NO), a strong vasodilator. Second, it can indirectly improve the function of endothelium and reduce the activity of the adrenergic system. Furthermore, it is suggested that melatonin can provide hypotensive effects by stimulating melatonin receptors in peripheral vessels and the central nervous system [41].

In this study, melatonin consumption for eight weeks significantly decreased weight, WC, $\mathrm{HC}, \mathrm{BMI}, \mathrm{WHR}, \mathrm{AVI}, \mathrm{BAI}$, and conicity index post-intervention. AVI is considered as an important indicator to evaluate fat accumulation in the abdominal region [42]. In Ehrampoush et al.'s study, it was indicated that AVI had the greatest correlation with body fat percentage [31]. There is no need to consider body weight in the calculation of BAI and AVI [43]. Conicity is more associated with body fat in men compared to women [31]. In addition, melatonin supplementation significantly increased ABSI, which can adjust WC for height and weight, while it shows a strong correlation with mortality rates [28]. The study performed by Amstrup et al. on postmenopausal women indicated that 1 year of treatment with melatonin (1 or $3 \mathrm{mg}$ per night) reduced fat mass [44]. Koziróg et al. in a research on patients with metabolic syndrome reported significant reduction in BMI after consuming melatonin supplement (5 mg/d for 2 months) [45]. In Mesri Alamdari et al.'s study, the participants were supplemented with a daily dose of $6 \mathrm{mg}$ of melatonin along with a low-calorie diet for 40 days. The results revealed that all the participants had significantly reduced weight, BMI, and waist and hip circumference [46]. Similarly, Szewczyk-Golec et al. administered a 30-day calorie-restricted diet combined with melatonin supplementation for obese individuals and reported significant weight loss without affecting BMI [47]. To the best of our knowledge, this study was the first to evaluate the effects of melatonin on new anthropometric indices. A majority of previous studies used weight and BMI as the outcomes of the study. However, our findings confirmed the effect of melatonin on weight control. It is indicated that these indices are considered as more useful indices to predict the risk of CVD compared with the other anthropometric indices. Hence, AVI, conicity, ABSI, BAl, and WHR along with BMI can be utilized as an investigative tool in the field to detect problems associated with T2DM and monitor the improvements.

There are several physiologic actions suggested for melatonin's contribution to weight reduction [20]. Firstly, its effect on sleep quality and also the regulation of appetite can impact food intake [13,44]. In addition, melatonin can impact both brown and white adipose tissue and play a controlling role in energy flow from the adipose tissue, so it can regulate the metabolic rate and energy balance [48, 49]. Also, some studies on aged subjects and shift workers indicated that low levels of melatonin can induce sleep disorder, insulin resistance, glucose intolerance, and metabolic circadian disorganization, characterizing a state of chronodisruption leading to obesity $[20,50]$.

There were some limitations to this study, including the short duration of the intervention. Moreover, several exclusion criteria may have limited the generalizability of the results. Therefore, further studies with longer interventions and a larger trial with some form of stratification are required to confirm the positive effects of melatonin supplementation on the management of diabetes. 


\section{Conclusion}

It is concluded that melatonin supplementation may be effective in controlling arterial blood pressure and improving the anthropometric indices in T2DM patients.

\section{Abbreviations}

TG; triglyceride, HDL; high-density lipoprotein, LDL; low-density lipoprotein cholesterol, MAP= mean arterial pressure; $\mathrm{PP}=$ pulse pressure; $\mathrm{AIP}=$ atherogenic index of plasma; $\mathrm{ABSI}=\mathrm{a}$ body shape index; $\mathrm{AVI}$ = abdominal volume index; BAI = body adiposity index; LAP = lipid accumulation product

\section{Declarations}

\section{Ethics approval and consent to participate}

An informed consent was obtained from all participants. The study was approved by ethics committee of Ahvaz Jundishapur University of Medical Sciences (Ref No. IR.AJUMS.REC.1397.897).

\section{Consent for publication}

Not applicable

\section{Availability of data and materials}

All the data is contained in the manuscript.

\section{Competing interests}

All other authors have no conflict of interest

\section{Funding}

This research project was sponsored by the Student Research Committee of Ahvaz Jundishapur University of Medical Sciences (97s43).

\section{Authors' contributions}

HB and AZJ wrote the study protocol and study design. HB and PA analyzed and interpreted the data. BMP, HBB, and FM helped with the sampling. PA and HB were involved in drafting the manuscript or revising it critically for content. All authors have given final approval of the version to be published.

\section{Acknowledgements}

We the authors, gratefully acknowledge all the patients who collaborated with us in this research work.

\section{Authors' information}

1. Student Research Committee, Ahvaz Jundishapur University of Medical Science, Ahvaz, Iran

2. Department of Nutrition, School of Allied Medical Sciences, Ahvaz Jundishapur University of Medical Sciences, Ahvaz, Iran 3.Student Research Committee, Tabriz University of Medical Science, Tabriz, Iran 


\section{References}

1. Haffner, S.M., et al., Mortality from coronary heart disease in subjects with type 2 diabetes and in nondiabetic subjects with and without prior myocardial infarction. New England journal of medicine, 1998. 339(4): p. 229234.

2. Leon, B.M. and T.M. Maddox, Diabetes and cardiovascular disease: Epidemiology, biological mechanisms, treatment recommendations and future research. World journal of diabetes, 2015. 6(13): p. 1246.

3. Bener, A., et al., Lipids, lipoprotein (a) profile and HbA1c among Arabian Type 2 diabetic patients. Biomedical Research, 2007. 18(2).

4. Cai, G., et al., The atherogenic index of plasma is a strong and independent predictor for coronary artery disease in the Chinese Han population. Medicine, 2017. 96(37).

5. Khazaal, M.S., Atherogenic Index of Plasma (AIP) as a parameter in predicting cardiovascular risk in males compared to the conventional dyslipidemic indices (cholesterol ratios). Karbala journal of medicine, 2013. 6(1): p. 1506-1513.

6. Christodoulakos, G.E., et al., Differential effect of hormone therapy and tibolone on lipids, lipoproteins, and the atherogenic index of plasma. Journal of cardiovascular pharmacology, 2006. 47(4): p. 542-548.

7. Okpa, H.O., et al., Comparative analysis of atherogenic index of plasma and its relationship with cardiovascular risk among patients with diabetes mellitus and concurrent diabetes mellitus with hypertension attending endocrinology clinic in a tertiary hospital south-south Nigeria. atherosclerosis, 2015. 13(15): p. 16.

8. Yu, D. and D. Simmons, Association between pulse pressure and risk of hospital admissions for cardiovascular events among people with Type 2 diabetes: a population-based case-control study. Diabetic Medicine, 2015. 32(9): p. 1201-1206.

9. Kengne, A.-P., et al., Blood pressure variables and cardiovascular risk: new findings from ADVANCE. Hypertension, 2009. 54(2): p. 399-404.

10. Verges, B., Dyslipidaemia in diabetes mellitus. prevalence, 1999. 13(14): p. 15.

11. Betteridge, D., Diabetic dyslipidaemia. European journal of clinical investigation, 1999. 29: p. 12-16.

12. Reiter, R.J., Pineal melatonin: cell biology of its synthesis and of its physiological interactions. Endocrine reviews, 1991. 12(2): p. 151-180.

13. Hardeland, R., et al., Melatonin, the circadian multioscillator system and health: the need for detailed analyses of peripheral melatonin signaling. Journal of pineal research, 2012. 52(2): p. 139-166.

14. Galano, A., D.X. Tan, and R.J. Reiter, On the free radical scavenging activities of melatonin's metabolites, AFMK and $A M K$. Journal of pineal research, 2013. 54(3): p. 245-257.

15. Cardinali, D.P., et al., Melatonin and its analogs in insomnia and depression. Journal of pineal research, 2012. 52(4): p. 365-375.

16. Calvo, J.R., C. Gonzalez-Yanes, and M. Maldonado, The role of melatonin in the cells of the innate immunity: a review. Journal of pineal research, 2013. 55(2): p. 103-120.

17. Mukherjee, D., et al., Melatonin protects against isoproterenol-induced myocardial injury in the rat: antioxidative mechanisms. Journal of pineal research, 2010. 48(3): p. 251-262.

18. Simko, F. and L. Paulis, Melatonin as a potential antihypertensive treatment. Journal of pineal research, 2007. 42(4): p. 319-322. 
19. Erşahin, M., et al., Melatonin improves cardiovascular function and ameliorates renal, cardiac and cerebral damage in rats with renovascular hypertension. Journal of pineal research, 2009. 47(1): p. 97-106.

20. Cipolla-Neto, J., et al., Melatonin, energy metabolism, and obesity: a review. Journal of pineal research, 2014. 56(4): p. 371-381.

21. Nduhirabandi, F., et al., Chronic melatonin consumption prevents obesity-related metabolic abnormalities and protects the heart against myocardial ischemia and reperfusion injury in a prediabetic model of diet-induced obesity. Journal of pineal research, 2011. 50(2): p. 171-182.

22. Puchalski, S.S., J.N. Green, and D.D. Rasmussen, Melatonin effect on rat body weight regulation in response to high-fat diet at middle age. Endocrine, 2003. 21(2): p. 163-167.

23. Lee, C.M.Y., et al., Indices of abdominal obesity are better discriminators of cardiovascular risk factors than BMI: a meta-analysis. Journal of clinical epidemiology, 2008. 61(7): p. 646-653.

24. Woo, J., et al., Is waist circumference a useful measure in predicting health outcomes in the elderly? International journal of obesity, 2002. 26(10): p. 1349.

25. Hsieh, S.D. and T. Muto, Metabolic syndrome in Japanese men and women with special reference to the anthropometric criteria for the assessment of obesity: Proposal to use the waist-to-height ratio. Preventive medicine, 2006. 42(2): p. 135-139.

26. Shiwaku, K., et al., Predictive values of anthropometric measurements for multiple metabolic disorders in Asian populations. Diabetes research and clinical practice, 2005. 69(1): p. 52-62.

27. Zimmet, P., et al., The metabolic syndrome: a global public health problem and a new definition. Journal of atherosclerosis and thrombosis, 2005. 12(6): p. 295-300.

28. Krakauer, N.Y. and J.C. Krakauer, A new body shape index predicts mortality hazard independently of body mass index. PloS one, 2012. 7(7): p. e39504.

29. Krakauer, N.Y. and J.C. Krakauer, An anthropometric risk index based on combining height, weight, waist, and hip measurements. Journal of obesity, 2016. 2016.

30. Mahan, L., S. Escott-Stump, and J. Raymond, Krause's Food \& the Nutrition Care Process,(Krause's Food \& Nutrition Therapy). 2012, Philadelphia: WB Saunders. Elsevier.

31. Ehrampoush, E., et al., New anthropometric indices or old ones: Which is the better predictor of body fat? Diabetes \& Metabolic Syndrome: Clinical Research \& Reviews, 2017. 11(4): p. 257-263.

32. Ramezanpour, M.R., E. Hosseini, and S. Naghibi, The short-term effects of melatonin supplement consumption on some cardiac parameters of active young women before, during and after exhaustive activity. medical journal of mashhad university of medical sciences, 2014. 57(2): p. 512-521.

33. Hoyos, M., et al., Serum cholesterol and lipid peroxidation are decreased by melatonin in diet-induced hypercholesterolemic rats. Journal of pineal research, 2000. 28(3): p. 150-155.

34. Pan, M., et al., Melatonin ameliorates nonalcoholic fatty liver induced by high-fat diet in rats. Journal of pineal research, 2006. 41(1): p. 79-84.

35. Sanchez-Mateos, S., et al., Melatonin and estradiol effects on food intake, body weight, and leptin in ovariectomized rats. Maturitas, 2007. 58(1): p. 91-101.

36. Kędziora-Kornatowska, K., et al., Melatonin improves oxidative stress parameters measured in the blood of elderly type 2 diabetic patients. Journal of pineal research, 2009. 46(3): p. 333-337.

37. Garfinkel, D., et al., Efficacy and safety of prolonged-release melatonin in insomnia patients with diabetes: a randomized, double-blind, crossover study. Diabetes, metabolic syndrome and obesity: targets and therapy, 
2011. 4: p. 307.

38. Tamura, H., et al., Melatonin treatment in peri-and postmenopausal women elevates serum high-density lipoprotein cholesterol levels without influencing total cholesterol levels. Journal of pineal research, 2008. 45(1): p. 101-105.

39. Rezvanfar, M.R., et al., Effect of bedtime melatonin consumption on diabetes control and lipid profile. International Journal of Diabetes in Developing Countries, 2017. 37(1): p. 74-77.

40. Możdżan, M., et al., The effect of melatonin on circadian blood pressure in patients with type 2 diabetes and essential hypertension. Archives of medical science: AMS, 2014. 10(4): p. 669.

41. Paulis, L. and F. Šimko, Blood pressure modulation and cardiovascular protection by melatonin: potential mechanisms behind. Physiological research, 2007. 56(6).

42. Vuga, M., Conceptual review of issues with practical abdominal obesity measures. Section on Statistics in Epidemiology-JSM, 2009.

43. López, A.A., et al., Body adiposity index utilization in a Spanish Mediterranean population: comparison with the body mass index. PloS one, 2012. 7(4): p. e35281.

44. Amstrup, A.K., et al., Reduced fat mass and increased lean mass in response to 1 year of melatonin treatment in postmenopausal women: A randomized placebo-controlled trial. Clinical endocrinology, 2016. 84(3): p. 342347.

45. Koziróg, M., et al., Melatonin treatment improves blood pressure, lipid profile, and parameters of oxidative stress in patients with metabolic syndrome. Journal of pineal research, 2011. 50(3): p. 261-266.

46. Alamdari, N.M., et al., A double-blind, placebo-controlled trial related to the effects of melatonin on oxidative stress and inflammatory parameters of obese women. Hormone and Metabolic Research, 2015. 47(07): p. 504508.

47. Szewczyk-Golec, K., et al., Melatonin supplementation lowers oxidative stress and regulates adipokines in obese patients on a calorie-restricted diet. Oxidative medicine and cellular longevity, 2017. 2017.

48. Jiménez-Aranda, A., et al., Melatonin induces browning of inguinal white adipose tissue in Zucker diabetic fatty rats. Journal of pineal research, 2013. 55(4): p. 416-423.

49. Tan, D.X., et al., Significance and application of melatonin in the regulation of brown adipose tissue metabolism: relation to human obesity. Obesity Reviews, 2011. 12(3): p. 167-188.

50. Alonso-Vale, M.I.C., et al., Melatonin and the circadian entrainment of metabolic and hormonal activities in primary isolated adipocytes. Journal of pineal research, 2008. 45(4): p. 422-429.

\section{Tables}

Table 1: The characteristics of subjects at baseline 


\begin{tabular}{|llll|}
\hline Variable & $\begin{array}{l}\text { Control group } \\
(\mathrm{n}=25)\end{array}$ & $\begin{array}{l}\text { Intervention group } \\
(\mathrm{n}=25)\end{array}$ & ${ }^{*} \mathrm{P}$-value \\
\hline Age (years) & $51.52 \pm 6.38$ & $53.64 \pm 4.82$ & 0.19 \\
\hline Female / Male $(\mathrm{N})$ & $18 / 7$ & $16 / 9$ & $0.54^{\text {** }}$ \\
\hline Disease duration (years) & $7.36 \pm 2.70$ & $7.92 \pm 2.48$ & 0.44 \\
\hline Physical Activity (met-min/ week) & $314.16 \pm 165.44$ & $303.64 \pm 177.36$ & 0.82 \\
\hline Weight $(\mathrm{kg})$ & $72.84 \pm 6.70$ & $73.88 \pm 8.85$ & 0.64 \\
\hline Height $(\mathrm{m})$ & $1.63 \pm 0.08$ & $1.64 \pm 0.07$ & 0.66 \\
\hline BMI $\left(\mathrm{kg} / \mathrm{m}^{2}\right)$ & $27.42 \pm 2.01$ & $27.38 \pm 2.16$ & 0.94 \\
\hline WC $(\mathrm{cm})$ & $102.00 \pm 8.45$ & $101.60 \pm 10.07$ & 0.88 \\
\hline HC $(\mathrm{cm})$ & $107.80 \pm 8.69$ & $106.76 \pm 10.04$ & 0.69 \\
\hline SBP $(\mathrm{mmHg})$ & $120.80 \pm 16.30$ & $124.00 \pm 15.27$ & 0.47 \\
\hline DBP $(\mathrm{mmHg})$ & $74.80 \pm 9.62$ & $74.00 \pm 8.66$ & 0.75 \\
\hline MAP $(\mathrm{mmHg})$ & $90.13 \pm 10.56$ & $90.66 \pm 9.90$ & 0.85 \\
\hline PP $(\mathrm{mmHg})$ & $46.00 \pm 13.22$ & $50.00 \pm 11.54$ & 0.26 \\
\hline HDL-c $(\mathrm{mg} / \mathrm{dl})$ & $42.36 \pm 11.10$ & $43.88 \pm 7.56$ & 0.57 \\
\hline TG $(\mathrm{mg} / \mathrm{dl})$ & $141.64 \pm 41.47$ & $161.12 \pm 48.71$ & 0.13 \\
\hline AIP & $0.52 \pm 0.18$ & $0.55 \pm 0.11$ & 0.42 \\
\hline LAP & $66.68 \pm 23.61$ & $77.74 \pm 39.57$ & 0.23 \\
\hline ABSI (m $\left.{ }^{11 / 6} \mathrm{Kg}{ }^{-2 / 3}\right)$ & $0.037 \pm 0.009$ & $0.037 \pm 0.005$ & 0.85 \\
\hline AVI & $20.94 \pm 3.38$ & $20.84 \pm 4.10$ & 0.92 \\
\hline BAl $\left(\mathrm{Kg} / \mathrm{m}^{2}\right)$ & $32.88 \pm 4.31$ & $32.95 \pm 5.68$ & 0.96 \\
\hline Conicity & $1.40 \pm 0.10$ & $1.42 \pm 0.08$ & 0.44 \\
\hline Waist to height ratio & $0.62 \pm 0.05$ & $0.61 \pm 0.05$ & 0.66 \\
\hline
\end{tabular}

Values are expressed as means \pm SD. $P<0.05$ was considered as significant.

${ }^{*} P<0.05$ was considered as significant using Independent T-test between the two groups at baseline.

$* * P<0.05$ was considered as significant using chi-square test

$\mathrm{BMI}=$ body mass index; $\mathrm{WC}=$ Waist circumference; $\mathrm{HC}=$ Hip circumference; $\mathrm{SBP}=$ systolic blood pressure; $\mathrm{DBP}=$ diastolic blood pressure; $\mathrm{MAP}=$ Mean Arterial Pressure; $\mathrm{PP}=$ pulse pressure; $\mathrm{TG}=$ triglyceride; $\mathrm{HDL}-\mathrm{C}=$ high density lipoprotein cholesterol; $\mathrm{AIP}=$ atherogenic index of plasma; $\mathrm{ABSI}=\mathrm{A}$ body shape index; $\mathrm{AVI}=\mathrm{Abdominal}$ volume index; $\mathrm{BAI}=$ Body adiposity index; $\mathrm{LAP}=$ Lipid Accumulation Product 
Table 2. Mean \pm SD of energy, carbohydrate, protein, fat intake at baseline and post-intervention

\begin{tabular}{|lllll|}
\hline Variable & & Baseline & post-intervention & $P$-value \\
Energy $(\mathrm{kcal} / \mathrm{d})$ & Control group & $1876.37 \pm 158.34$ & $1887.87 \pm 176.99$ & 0.97 \\
& Intervention group & $1924.83 \pm 173.41$ & $1875.74 \pm 156.84$ & 0.059 \\
& $P$-value* & 0.30 & 0.79 & \\
\hline Carbohydrate $(\mathrm{g} / \mathrm{d})$ & Control group & $250.74 \pm 22.62$ & $248.65 \pm 22.65$ & 0.92 \\
& Intervention group & $244.64 \pm 21.02$ & $244.34 \pm 20.32$ & 0.44 \\
& $P$-value* & 0.32 & 0.48 & \\
\hline Protein $(\mathrm{g} / \mathrm{d})$ & Control group & $76.83 \pm 6.37$ & $75.69 \pm 6.30$ & 0.91 \\
& Intervention group & $74.97 \pm 6.39$ & $74.86 \pm 6.09$ & 0.14 \\
& $P$-value* & 0.30 & 0.63 & 0.43 \\
\hline Fat $(\mathrm{g} / \mathrm{d})$ & Control group & $68.15 \pm 5.69$ & $67.18 \pm 5.68$ & 0.16 \\
& Intervention group & $66.71 \pm 5.81$ & $67.35 \pm 5.87$ & \\
\hline & $P$-value* & 0.38 & 0.91 & \\
\hline
\end{tabular}

${ }^{\star} P<0.05$ was considered as significant using Independent T-test between the two groups post-intervention.

** $P<0.05$ was considered as significant using Paired T-test.

Table 3. Atherogenic index of plasma, mean arterial pressure, pulse pressure and old and new anthropometric indices at baseline and post-intervention. 


\begin{tabular}{|c|c|c|c|c|c|c|c|c|c|}
\hline \multirow[t]{2}{*}{ Variable } & \multicolumn{3}{|c|}{ Control group $(n=25)$} & \multicolumn{3}{|c|}{ Intervention group $(n=25)$} & \multirow{2}{*}{$\begin{array}{l}{ }^{*} P- \\
\text { value }\end{array}$} & \multirow{2}{*}{$\begin{array}{l}{ }^{* *}{ }^{*}- \\
\text { value }\end{array}$} & \multirow{2}{*}{${ }^{* *} P$ - } \\
\hline & Baseline & $\begin{array}{l}\text { After } \\
8 \text { weeks }\end{array}$ & $\begin{array}{l}P- \\
\text { value }\end{array}$ & Baseline & $\begin{array}{l}\text { After } \\
8 \text { weeks }\end{array}$ & $\begin{array}{l}P- \\
\text { value }\end{array}$ & & & \\
\hline Weight (kg) & $\begin{array}{l}72.84 \pm \\
6.70\end{array}$ & $72.98 \pm 6.78$ & 0.75 & $\begin{array}{l}73.88 \pm \\
8.85\end{array}$ & $\begin{array}{l}70.28 \pm \\
7.57\end{array}$ & 0.001 & 0.19 & 0.12 & \\
\hline Changes & \multicolumn{3}{|c|}{$-1.00(-1.00,1.00)$} & \multicolumn{3}{|c|}{$-3.00(-6.50,-1.50)$} & & & $\begin{array}{l}< \\
0.001\end{array}$ \\
\hline $\begin{array}{l}\text { BMI } \\
\left(\mathrm{kg} / \mathrm{m}^{2}\right)\end{array}$ & $\begin{array}{l}27.42 \pm \\
2.01\end{array}$ & $27.47 \pm 2.03$ & 0.76 & $\begin{array}{l}27.38 \pm \\
2.16\end{array}$ & $\begin{array}{l}26.11 \pm \\
2.39\end{array}$ & 0.002 & 0.03 & 0.04 & \\
\hline Changes & \multicolumn{3}{|c|}{$-0.30(-0.39,0.42)$} & \multicolumn{3}{|c|}{$-1.17(-2.40,-0.51)$} & & & $\begin{array}{l}< \\
0.001\end{array}$ \\
\hline WC $(\mathrm{cm})$ & $\begin{array}{l}102.00 \\
\pm 8.45\end{array}$ & $\begin{array}{l}102.00 \pm \\
8.18\end{array}$ & 1.00 & $\begin{array}{l}101.60 \\
\pm 10.07\end{array}$ & $\begin{array}{l}99.48 \pm \\
9.54\end{array}$ & 0.01 & 0.32 & 0.21 & \\
\hline Changes & \multicolumn{3}{|c|}{$0.00(-1.00,1.00)$} & \multicolumn{3}{|c|}{$-1.00(-3.00,0.00)$} & & & 0.003 \\
\hline $\mathrm{HC}(\mathrm{cm})$ & $\begin{array}{l}107.80 \\
\pm 8.69\end{array}$ & $\begin{array}{l}107.10 \pm \\
7.17\end{array}$ & 0.45 & $\begin{array}{l}106.76 \\
\pm 10.04\end{array}$ & $\begin{array}{l}103.04 \pm \\
9.32\end{array}$ & 0.001 & 0.09 & 0.10 & \\
\hline Changes & \multicolumn{3}{|c|}{$0.00(-1.00,1.00)$} & \multicolumn{3}{|c|}{$-2.00(-5.00,-1.00)$} & & & $\stackrel{<}{<.001}$ \\
\hline $\begin{array}{l}\text { MAP } \\
(\mathrm{mmHg})\end{array}$ & $\begin{array}{l}90.13 \\
\pm 10.56\end{array}$ & $\begin{array}{l}91.33 \pm \\
8.81\end{array}$ & 0.39 & $\begin{array}{l}90.66 \pm \\
9.90\end{array}$ & $\begin{array}{l}84.80 \pm \\
8.33\end{array}$ & 0.003 & 0.01 & 0.009 & \\
\hline Changes & \multicolumn{3}{|c|}{$0.00(-3.33,3.33)$} & \multicolumn{3}{|c|}{$-3.33(-10.00,0.00)$} & & & 0.005 \\
\hline $\mathrm{PP}(\mathrm{mmHg})$ & $\begin{array}{l}46.00 \pm \\
13.22\end{array}$ & $\begin{array}{l}47.20 \pm \\
12.08\end{array}$ & 0.47 & $\begin{array}{l}50.00 \pm \\
11.54\end{array}$ & $\begin{array}{l}44.40 \pm \\
11.21\end{array}$ & 0.02 & 0.40 & 0.63 & \\
\hline Changes & \multicolumn{3}{|c|}{$0.00(-10.00,10.00)$} & \multicolumn{3}{|c|}{$0.00(-10.00,0.00)$} & & & 0.03 \\
\hline AIP & $\begin{array}{l}0.52 \pm \\
0.18\end{array}$ & $0.53 \pm 0.18$ & 0.62 & $\begin{array}{l}0.55 \pm \\
0.11\end{array}$ & $\begin{array}{l}0.49 \pm \\
0.15\end{array}$ & 0.06 & 0.45 & 0.63 & \\
\hline Changes & \multicolumn{3}{|c|}{$0.01(-0.04,0.08)$} & \multicolumn{3}{|c|}{$-0.08(-0.15,0.05)$} & & & 0.10 \\
\hline $\begin{array}{l}\text { LAP } \\
\text { (cm.mmol.I) }\end{array}$ & $\begin{array}{l}66.68 \pm \\
23.61\end{array}$ & $\begin{array}{l}68.00 \pm \\
26.42\end{array}$ & 0.64 & $\begin{array}{l}77.74 \pm \\
39.57\end{array}$ & $\begin{array}{l}71.20 \pm \\
32.26\end{array}$ & 0.22 & 0.70 & 0.54 & \\
\hline Changes & \multicolumn{3}{|c|}{$-1.71(-8.28,11.17)$} & \multicolumn{3}{|c|}{$-3.06(-23.87,14.34)$} & & & 0.42 \\
\hline $\begin{array}{l}\text { ABSI } \\
\left(\begin{array}{l}\mathrm{m} 11 / 6 . \mathrm{Kg}- \\
2 / 3\end{array}\right)\end{array}$ & $\begin{array}{l}0.037 \pm \\
0.009\end{array}$ & $\begin{array}{l}0.036 \pm \\
0.008\end{array}$ & 0.12 & $\begin{array}{l}0.037 \pm \\
0.005\end{array}$ & $\begin{array}{l}0.04 \pm \\
0.004\end{array}$ & $<0.001$ & 0.05 & 0.15 & \\
\hline Changes & \multicolumn{3}{|c|}{$0.000(-0.001,0.001)$} & \multicolumn{3}{|c|}{$0.002(0.001,0.005)$} & & & $\stackrel{<}{<.001}$ \\
\hline $\mathrm{AVI}$ & $20.94 \pm$ & $20.93 \pm$ & 0.96 & $20.84 \pm$ & $19.96 \pm$ & 0.01 & 0.34 & 0.23 & \\
\hline
\end{tabular}




\begin{tabular}{|c|c|c|c|c|c|c|c|c|c|}
\hline & 3.38 & 3.28 & & 4.10 & 3.85 & & & & \\
\hline Changes & \multicolumn{3}{|c|}{$0.00(-0.42,0.40)$} & \multicolumn{5}{|c|}{$-0.45(-1.10,0.00)$} & 0.004 \\
\hline $\begin{array}{l}\mathrm{BAl} \\
\left(\mathrm{Kg} / \mathrm{m}^{2}\right)\end{array}$ & $\begin{array}{l}32.88 \pm \\
4.31\end{array}$ & $\begin{array}{l}31.72 \pm \\
3.59\end{array}$ & 0.07 & $\begin{array}{l}32.95 \pm \\
5.68\end{array}$ & $\begin{array}{l}29.74 \pm \\
4.56\end{array}$ & $<0.001$ & 0.09 & 0.07 & \\
\hline Changes & \multicolumn{3}{|c|}{$-1.04(-3.33,0.45)$} & \multicolumn{5}{|c|}{$-3.38(-5.36,-0.92)$} & 0.04 \\
\hline Conicity & $\begin{array}{l}1.40 \pm \\
0.10\end{array}$ & $\begin{array}{l}1.39 \pm \\
0.10\end{array}$ & 0.90 & $\begin{array}{l}1.42 \pm \\
0.08\end{array}$ & $\begin{array}{l}1.39 \pm \\
0.08\end{array}$ & 0.001 & 0.88 & 0.56 & \\
\hline Changes & \multicolumn{3}{|c|}{$0.00(-0.01,0.01)$} & \multicolumn{5}{|c|}{$-0.01(-0.04,0.00)$} & 0.003 \\
\hline $\begin{array}{l}\text { Waist to } \\
\text { height ratio }\end{array}$ & $\begin{array}{l}0.62 \pm 0.05 \\
0.04\end{array}$ & $0.62 \pm$ & 0.98 & $\begin{array}{l}0.61 \pm \\
0.05\end{array}$ & $\begin{array}{l}0.60 \pm \\
0.05\end{array}$ & 0.02 & 0.21 & 0.15 & \\
\hline Changes & \multicolumn{3}{|c|}{$0.000(-0.006,0.006)$} & \multicolumn{5}{|c|}{$-0.006(-0.018,0.000)$} & 0.01 \\
\hline
\end{tabular}

Values are expressed as means \pm SD for normal data and median (Q1-Q3) for abnormal data.

$P<0.05$ was considered as significant using Paired T-test.

* $P<0.05$ was considered as significant using Independent T-test between the two groups post-intervention (crude model)

** $P<0.05$ was considered as significant using Analysis of covariance (ANCOVA) between the two groups postintervention after the adjustment for confounding factors (model 1)

***.P $<0.05$ was considered as significant changes using Mann-Whitney $U$ test between the two groups postintervention

$\mathrm{BMI}=$ body mass index; $\mathrm{WC}=$ Waist circumference; $\mathrm{HC}=$ Hip circumference; $\mathrm{MAP}=$ Mean Arterial Pressure; $\mathrm{PP}=$ pulse pressure; $\mathrm{TG}=$ triglyceride; $\mathrm{HDL}-\mathrm{c}=$ high-density lipoprotein cholesterol; $\mathrm{AIP}=$ atherogenic index of plasma;

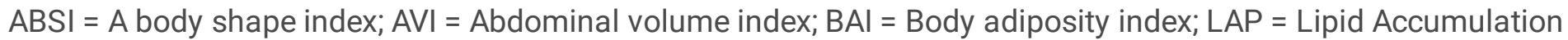
Product

\section{Figures}




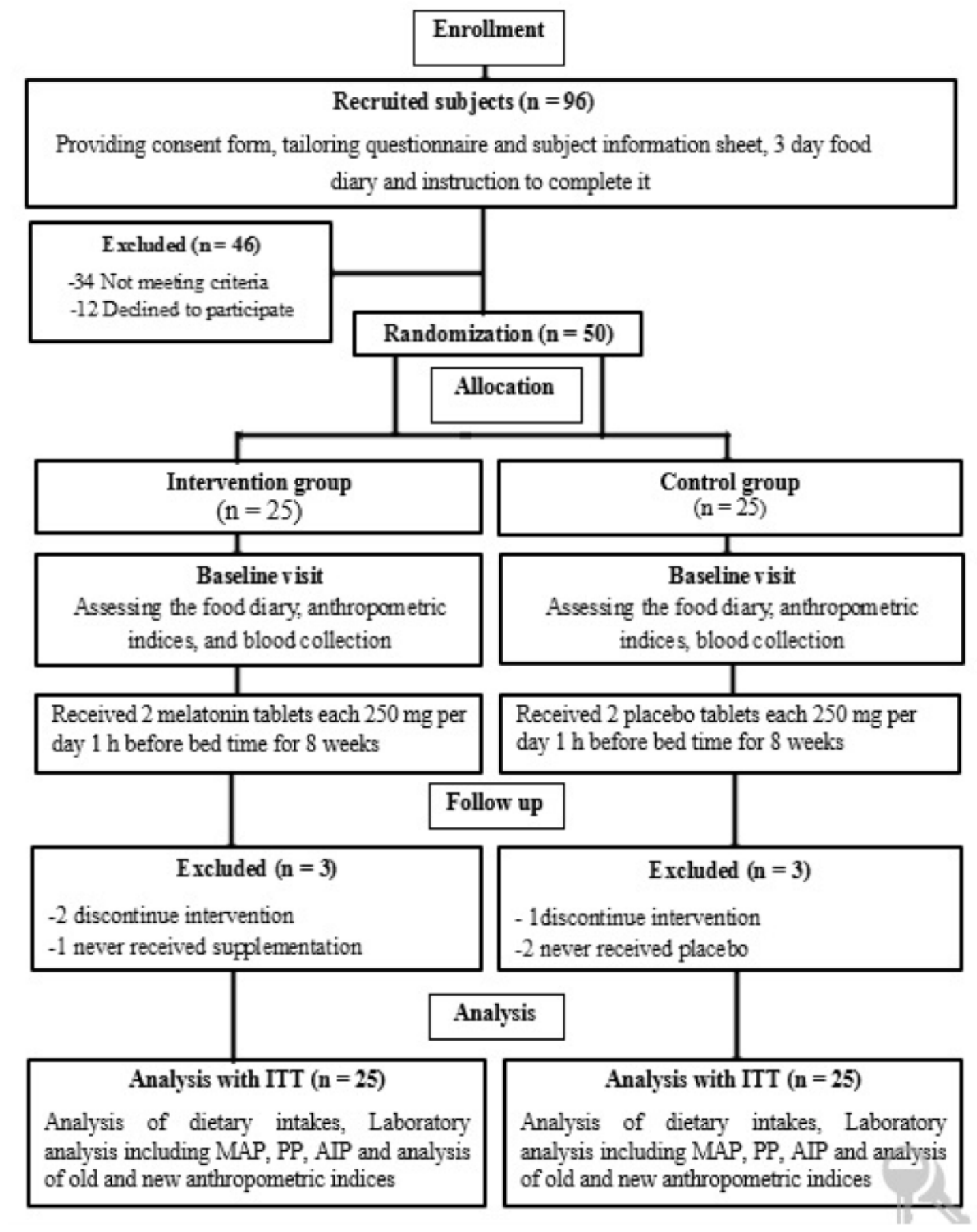

\section{Figure 1}

Stages of clinical trial progress Abbreviations: triglycerid (TG), low-density lipoprotein cholesterol (LDL-C), systolic blood pressure (SBP), diastolic blood pressure (DBP), mean arterial pressure (MAP), pulse pressure (PP) and atherogenic index of plasma (AIP) 